\title{
Local Diversity and Biting Pattern of Anopheles Species in Southern Minahasa
}

\author{
O. R. Pinontoan, ${ }^{1}$ I. G. P. Supadmanaba, ${ }^{2}$ I. B. A. Manuaba, ${ }^{3}$ \\ I. D. M. Sukrama, ${ }^{4}$ and I. B. P. Manuaba ${ }^{5}$ \\ ${ }^{1}$ Department of Entomology, Graduate Programme, Sam Ratulangi University, Manado, Indonesia \\ ${ }^{2}$ Biochemistry Department, Faculty of Medicine, Udayana University, Denpasar, Bali, Indonesia \\ ${ }^{3}$ Department of Medical Education, Faculty of Medicine, Udayana University, Denpasar, Bali, Indonesia \\ ${ }^{4}$ Department of Microbiology, Faculty of Medicine, Udayana University, Denpasar, Bali, Indonesia \\ ${ }^{5}$ Biomedicine Postgraduate Program, Udayana University, Bali, Indonesia
}

Correspondence should be addressed to O. R. Pinontoan; odipinontoan@yahoo.com

Received 27 February 2017; Revised 12 May 2017; Accepted 11 June 2017; Published 6 August 2017

Academic Editor: Subhada Prasad Pani

Copyright (C) 2017 O. R. Pinontoan et al. This is an open access article distributed under the Creative Commons Attribution License, which permits unrestricted use, distribution, and reproduction in any medium, provided the original work is properly cited.

Background. To optimize the preventive measures of malaria, it is important to synchronize the efforts with the behavior of local Anopheles species. However, the data of Anopheles species and their behavior in Indonesia is still lacking. Method. Explorative research was conducted from April to September 2016 in Southern Minahasa district. The Anopheles mosquito was baited by using animal and human (indoor or outdoor) from 18.00 to 06.00 hours. Then, the species were identified and Man Biting Rate (MBR) and Man/Animal Biting per Hour (MBPH) were calculated followed by statistical analysis by using SPSS 17. Result. The data showed that the dominant species in Southern Minahasa were An. barbirostris, An. kochi, and An. vagus. An. vagus was found to be zoophilic and An. barbirostris was showing strict anthropophilic characteristics. Meanwhile, An. kochi feeds on both human and animal. The MBR of $A n$. kochi was found to be the highest $(P<0.005)$, but its MBPH only significantly exceeded that of An. vagus. All species tend to be more active during the early evening. Conclusion. An. barbirostris, An. kochi, and An. vagus were the dominant Anopheles species in Southern Minahasa. Further research is needed to determine the Plasmodium infestation rate of these species.

\section{Background}

The mosquito is known as a vector for some of the most important human parasites including malaria which is one of important communicable diseases especially in tropical area [1]. Global prevalence rate of malaria was estimated at 214 million cases with 438,000 deaths in 2015 [2]. It is also one of the main burdens of infectious disease in Indonesia with 209,413 new cases in 2015. It is particularly concentrated in Middle and Eastern Indonesia especially in Southern Minahasa which experienced a rise in malarial cases [3].

The diversity of Anopheles mosquito poses a real challenge to malaria control programs because different species tend to have different behaviors and feeding locations (indoor versus outdoor) [4]. For example, if predominant Anopheles species within the region tend to feed on human outdoor, then common preventive measures like insecticide-impregnated bed nets and indoor spraying will be useless to prevent malaria. Also, the zoophilic tendency is also important in the case of zoophilic-anthropophilic Anopheles since the presence of domestic animal near housing will only attract mosquito [5]. Furthermore, this type of Anopheles also increases the risk of zoonosis, such as in the case of $P$. knowlesi [6].

Since there are only few studies of Anopheles species in Indonesia, the exploration and mapping of Anopheles species and its distribution are important. Moreover, Indonesia is an archipelago country with each of its islands or regions having very distinct ecological characteristics from one another; thus it could be hypothesized that the Anopheles diversity will also differ from one area to another. So this type of research is urgently needed in Indonesia, especially in malaria endemic areas such as Southern Minahasa. 


\section{Methods}

A descriptive explorative research was conducted to identify Anopheles species in the region of South Minahasa district and evaluate whether the species are potential vector for malaria from April to September 2016 in South Minahasa district. Sampling was conducted in the areas suspected as Anopheles breeding ground for two weeks. Mosquitoes were baited using human and animal and then caught using insect net. The mosquitoes were then placed inside a labeled tube film, identified, and counted. The protocol of using human and animal bait is described as follows.

2.1. Human Bait. The mosquitoes were lured by using four people as human baits who worked in shifts between 18.00 and 06.00 hours. As a preventive measure, malaria prophylaxis (chloroquine) had been given one week before research and continued for up to 1 month after the end of the study. Sample collection was conducted both inside and outside the house from families that had at least one member with malaria. The human bait wore a short and rolled up the cloth sleeve, exposing the whole arm to the mosquito. The human bait was also asked not to smoke during the baiting period.

2.2. Animal Bait. Mosquito catching using animal baits was conducted in the animal pen and its surrounding areas with no special treatment given to the animal. All mosquitoes that landed on the animal were collected using aspirator and stored inside labeled container.

All collected specimens were identified using taxonomical book by O'Connor and Soepanto (1999) [7].

The density of mosquitoes that contact the human and animal bait was calculated by using following equation.

(a) The Man Biting Rate (Man Biting Rate) [8]:

the number of mosquitoes on human bait per night the number of catching attempts $\times$ period of catching activity

(b) Man/Animal Biting per Hour (MBPH) [9]:

the number of mosquitoes on human bait per hour

the number of catching attempts $\times$ period of catching activity

All data were analyzed descriptively to see the diversity of the species, the pattern of mosquito density, and its biting pattern. All data were analyzed by normality test (Shapiro-Wilk) to determine the distribution pattern. Next, we compared the density and biting pattern of each species to evaluate whether the differences were statistically significant. All analyses were conducted with SPSS.17 for Windows.

\section{Results}

3.1. Diversity Profile of Anopheles Mosquito Caught in Southern Minahasa. Table 1 describes the profile of Anopheles species that was found in Southern Minahasa as well as their respective frequency from May to September 2016.

It appeared that $A n$. barbirostris and An. parangensis were the most common species inside the house. Meanwhile, $A n$.
TABle 1: Profile of Anopheles mosquito species and the average number of each species with human and animal baits.

\begin{tabular}{lcccccccc}
\hline & \multicolumn{4}{c}{ Human bait } & \multicolumn{3}{c}{ Animal } \\
Period of catch & \multicolumn{3}{c}{ Indoor } & \multicolumn{3}{c}{ Outdoor } & \multicolumn{2}{c}{ bait } \\
& $(1)$ & $(2)$ & $(3)$ & $(1)$ & $(2)$ & $(3)$ & $(4)$ & $(5)$ \\
\hline May & 17 & 4 & 17 & 9 & 14 & 20 & 14 & 14 \\
June & 19 & 17 & 7 & 7 & 26 & 17 & 22 & 20 \\
July & 20 & 29 & 20 & 3 & 28 & 19 & 14 & 46 \\
August & 27 & 30 & 5 & 4 & 39 & 16 & 16 & 19 \\
September & 32 & 14 & 4 & 5 & 32 & 14 & 20 & 11 \\
\hline Average & 23 & 18.8 & 10.6 & 5.6 & 27.8 & 17.2 & 17.2 & 22 \\
\hline
\end{tabular}

Note. (1) An. barbirostris; (2) An. parangensis; (3) An. maculatus; (4) An. vagus; (5) An. kochi.

parangensis and An. maculatus were more common outside the house. It was interested that $A n$. parangensis was found to be quite common both inside and outside the house. No An. vagus or An. kochi was found in human bait experiment, but both of them were commonly found in animal bait experiment.

3.2. The Density and Biting Pattern of Anopheles Mosquito in Southern Minahasa. Next, we calculated the MBR of An. vagus, An. kochi, and An. barbirostris. The result of MBR of those species is described in detail in Tables 2, 3, and 4 . Because An. vagus feeds on animals, we calculate its MBR and MBPH based on the number of mosquitoes found feeding on domestic animals. Table 2 shows that the MBR of this species ranges from 0.3 to 0.9 mosquitoes per animal. Meanwhile, evaluation of $\mathrm{MBPH}$ revealed that the feeding activity of An. vagus took place between 18.00 and 22.00 hours with a momentary pause between 22.00 and 05.00 hours. Then, the feeding activity resumed briefly from 05.00 to 06.00 hours. The $\mathrm{MBPH}$ of this species ranged from 0.1 to 0.2 mosquitoes/animal/hour.

We evaluated the same variable for An. kochi. It appears that the MBR of An. kochi in animals ranges from 0.31 to 1.64, which was higher than that of An. vagus. Also, its $\mathrm{MBPH}$ ranged from 0.02 to 0.35 inside the house and 0.02 to 0.54 outside the house. MBPH data indicate that the feeding activity of An. kochi began as early as 06.00 a.m. and rose sharply in the next 2-hour period. Meanwhile, it decreased steadily for the next 2 hours until there was no detectable activity between 02.00 and 04.00 hours. Then, there was some feeding activity during the last 2-hour period. In contrast, the activity of $A n$. kochi outside the house was much higher during the first 6 hours. Later on, it decreased sharply and stabilized at 0.02 mosquitoes/man/hour. In contrast to $A n$. vagus, An. kochi is known to feed on both humans and animals, so the calculation of $\mathrm{MBPH}$ was focused on human bait.

We evaluated the corresponding variables for An. barbirostris, which is known to feed only on human. Compared to An. vagus and An. kochi, An. barbirostris has higher rate of MBR ranging from 0.71 to 0.89 inside the house and 0.11 to 0.45 outside the house. Meanwhile, its MBPH was 
TABLE 2: Man Biting Rate (MBR) of An. vagus, An. kochi, and An. barbirostris.

\begin{tabular}{|c|c|c|c|c|}
\hline \multirow{3}{*}{ Month } & \multicolumn{4}{|c|}{ Man Biting Rate (MBR) } \\
\hline & \multirow{2}{*}{$\begin{array}{c}\text { An. vagus } \\
\text { Animal bait }\end{array}$} & \multirow{2}{*}{$\begin{array}{c}\text { An. kochi } \\
\text { Animal bait }\end{array}$} & \multicolumn{2}{|c|}{ An. barbirostris } \\
\hline & & & Exophytic human bait & Endophytic human bait \\
\hline May & 0.7 & 0.7 & 0.45 & 0.85 \\
\hline June & 0.9 & 0,83 & 0.29 & 0.79 \\
\hline July & 0.5 & 1.64 & 0.11 & 0.71 \\
\hline August & 0.3 & 0.59 & 0.13 & 0.84 \\
\hline September & 0.6 & 0.31 & 0.14 & 0.89 \\
\hline
\end{tabular}

Table 3: Man/Animal Biting per Hour of An. vagus, An. kochi, and An. barbirostris.

\begin{tabular}{|c|c|c|c|c|c|c|}
\hline \multirow{3}{*}{$\begin{array}{l}\text { Timing } \\
\text { period }\end{array}$} & \multicolumn{6}{|c|}{ Man/Animal Biting per Hour (MBPH) } \\
\hline & \multicolumn{2}{|c|}{ An. vagus } & \multicolumn{2}{|c|}{ An. kochi } & \multicolumn{2}{|c|}{ An. barbirostris } \\
\hline & $\begin{array}{l}\text { Exophytic human } \\
\text { bait }\end{array}$ & $\begin{array}{c}\text { Endophytic human } \\
\text { bait }\end{array}$ & $\begin{array}{l}\text { Exophytic human } \\
\text { bait }\end{array}$ & $\begin{array}{c}\text { Endophytic human } \\
\text { bait }\end{array}$ & $\begin{array}{l}\text { Exophytic human } \\
\text { bait }\end{array}$ & $\begin{array}{l}\text { Endophytic human } \\
\text { bait }\end{array}$ \\
\hline $18.00-19.00$ & 0.1 & 0 & 0.29 & 0.02 & 0.31 & 0.17 \\
\hline $19.00-20.00$ & 0.2 & 0 & 0.46 & 0.35 & 0.56 & 0.35 \\
\hline $20.00-21.00$ & 0.2 & 0 & 0.54 & 0.29 & 0.35 & 0.15 \\
\hline $21.00-22.00$ & 0.1 & 0 & 0.39 & 0.14 & 0 & 0.04 \\
\hline $22.00-23.00$ & 0 & 0 & 0.39 & 0.10 & 0.21 & 0.02 \\
\hline $23.00-24.00$ & 0 & 0 & 0.33 & 0.06 & 0.04 & 0.02 \\
\hline $00.00-01.00$ & 0 & 0 & 0.13 & 0.04 & 0.04 & 0.02 \\
\hline $01.00-02.00$ & 0 & 0 & 0.02 & 0.02 & 0.02 & 0 \\
\hline $02.00-03.00$ & 0 & 0 & 0.02 & 0 & 0.02 & 0 \\
\hline $03.00-04.00$ & 0 & 0 & 0.02 & 0 & 0.02 & 0 \\
\hline $04.00-05.00$ & 0 & 0 & 0.02 & 0.02 & 0 & 0.04 \\
\hline $05.00-06.00$ & 0.1 & 0 & 0.02 & 0.08 & 0.08 & 0.08 \\
\hline
\end{tabular}

not so different than the other two. The MBR rate inside the house was also higher than the outside; meanwhile, the opposite was observed in $\mathrm{MBPH}$ rate for the first 5 hours. Then, the MBPH rate began to fall and stabilized at 0.02-0.04 mosquitoes/man/hour. Interestingly, no activity was observed between 01.00 and 04.00 hours.

3.3. Comparison of $M B R$ and $M B P H$ between An. vagus, $A n$. kochi, and An. barbirostris. Lastly, we compared both variables (MBR and $\mathrm{MBPH}$ ) between An. vagus, An. kochi, and $A n$. barbirostris. The details of comparisons are presented in Tables 4 and 5. From MBR perspective, it was clear that the exophytic density of An. vagus and An. kochi exceeded that of $A n$. barbirostris significantly. In addition, the endophytic density of An. barbirostris also exceeded its exophytic density.

Meanwhile, from MBPH data, it was clearly seen that only the difference between $\mathrm{MBPH}$ of An. vagus and exophytic An. kochi was statistically significant (Table 5). Considering that all species tend to be more active during the first half of the night, we decided to exclude the other 6-hour periods of observation from analysis (reanalysis; Table 5). On reanalysis, it appeared that the endophytic and exophytic activity of $A n$. kochi were significantly different. Meanwhile, no significant difference was observed between exophytic and endophytic An. barbirostris.
TABle 4: MBR comparison between An. vagus, An. kochi, and An. barbirostris.

\begin{tabular}{lcc}
\hline Species & Species comparison & $P$ value \\
\hline \multirow{3}{*}{ An. vagus } & An. kochi & 0.53 \\
& Endophytic An. barbirostris & 0.073 \\
& Exophytic An. barbirostris & 0.014 \\
\hline \multirow{2}{*}{ An. kochi } & Endophytic An. barbirostris & 0.251 \\
& Exophytic An. barbirostris & 0.016 \\
\hline Endophytic An. barbirostris & Exophytic An. barbirostris &
\end{tabular}

\section{Discussion}

Malaria is one of the most deadly and widespread parasitic disease in the world [2]. Many attempts had been made to control, prevent, and even eliminate the disease. One of them is by studying the species diversity and behavior of Anopheles mosquito, the vector of malaria [4]. This field of research is considered to be important because it could identify the specific species of Anopheles responsible for malaria transmission from human to human or animal to human and vice versa [6]. It could also contribute to malaria prevention by matching the preventive programs to predominant Anopheles species within the area [4]. 
TABLE 5: Comparison of MBPH between An. vagus, An. kochi, and An. barbirostris.

\begin{tabular}{lcccc}
\hline Species & Species comparison & Normality test (Shapiro-Wilk) & $P$ value & $P$ value (Reanalysis) \\
\hline \multirow{2}{*}{ An. vagus } & Exophytic An. kochi & 0.499 & $0.008^{*}$ & $0.000^{*}$ \\
& Exophytic An. barbirostris & 0.196 & 0.137 & 0.149 \\
Endophytic An. kochi & Exophytic An. kochi & 0.655 & 0.158 & $0.004^{*}$ \\
& Endophytic An. barbirostris & 0.185 & 0.619 & 0.651 \\
Exophytic An. kochi & Exophytic An. barbirostris & 0.169 & 0.331 & 0.126 \\
Endophytic An. barbirostris & Exophytic An. barbirostris & 0.177 & 0.464 & 0.258 \\
\hline
\end{tabular}

${ }^{*}$ Reanalysis. We only used MBPH data that pertained to the period 18.00-24.00 hours.

There are several interesting facts that we obtained from this exploratory study. We found there were five species of Anopheles in the Southern Minahasa region: An. barbirostris, An. parangensis, An. maculatus, An. vagus, and An. kochi. The first three species were found to feed on humans; meanwhile, the other two were found to only feed on animals. Meanwhile, An. kochi was found to feed on both humans and animals. The frequency of each species is shown in Table 1.

Our study results clearly showed that An. barbirostris and $A n$. kochi were the predominant species. This finding is different from that reported in studies conducted in other locations in Southeast Asia, such as Malaysia, Thailand, Vietnam, and Lao PDR, where it was reported that An. maculatus is the dominant species [6,10-12]. Similarly, Sumba Island, which is also in the Central Indonesia region, is dominated by another species, namely, An. sondaicus [13]. However, our results are indeed consistent with studies conducted by Ndoen et al. and Pinontoanetal (unpublished), but An. kochi was not considered to be a common species by both studies $[14,15]$. The reason for the discrepancy might be because the population of An. barbirostris, An. parangensis, and An. maculatus tends to be higher in populated areas, especially inside the house, which increases the chances of catching in this study $[4,14]$. Meanwhile, this study focused on the peripheral area which is less populated but close to shrub and jungle areas which are suitable breeding grounds for Anopheles. Therefore, the other two species were also caught.

By comparing their MBR and MBPH rates, all the analyzed species were considered potential vectors because their MBR rates exceeded the threshold level for vector, which is 0.025 mosquitoes/human/night [16]. However, An. vagus fed specifically only on domestic animals and showed no interest toward human. The preference of An. vagus for animals to humans was also reported by several other researches [5, $14,17,18]$. However, it had also been identified as malaria vector in some occasions, especially during outbreaks [19]. Furthermore, it was also found to bite people who live close to the cattle pen [18].

On the other hand, An. barbirostris was found to specifically feed on humans, which was confirmed by the absence of this species during the animal bait experiment. The density (MBR) of this species was higher than that of An. vagus but lower than that of $A n$. kochi, though the difference between it and An. vagus was not statistically significant. It was also found both inside and outside the house, but its endophytic MBR was significantly higher, which suggests that this species was more active indoor. Based on the pattern of its $\mathrm{MBPH}$, it was found that An. barbirostris tended to remain active during the first 4-5 hours of the evening. However, the $\mathrm{MBPH}$ pattern showed that this species was slightly more active outdoor. An. barbirostris is widely distributed in Southeast Asia and some studies had also confirmed it as a Plasmodium vector [20, 21]. However An. barbirostris was never found to be a common species in other studies conducted in Southeast Asia and its density had always exceeded the density of An. maculatus, An. sondaicus, and An. dirus $[6,10]$. Furthermore, Amerasinghe et al. and Reid et al. reported that it is the anthropophilic-zoophilic type which is contrary to our findings $[22,23]$.

As for the comparison of the last two Anopheles species, the feeding pattern of $A n$. kochi was found to be similar to that of An. barbirostris, but An. barbirostris was found feeding on both humans and animals. By comparing its MBR and $\mathrm{MBPH}$, it was clear that the density of this species exceeded the densities of the other two species. Furthermore, its exophytic feeding activity was also higher than its endophytic activity, although there were no statistically significant differences between its $\mathrm{MBPH}$ and that of $A n$. vagus and exophytic An. barbirostris. This species tends to be more widely distributed compared with other Anopheles species, which is confirmed by Pinontoan [15]. The same study had also stated that this species was invested with Plasmodium, which highlights the potential role of this species in malaria transmission. However, a study conducted in Maluku region of eastern Indonesia by Soekirno et al. reported that $A n$. kochi was not infectious and did not act as an effective vector for Plasmodium [24]. Jiram et al. also studied this species to find out whether it was susceptible to animal Plasmodium infection but could not find any sporozoite [6]. Thus, it remains unclear whether this species could act effectively as a Plasmodium vector and further researches are needed to confirm the findings reported by Pinontoan [15].

Overall, our findings reveal the local diversity in Southern Minahasa region of Celebes Island, Indonesia. This finding was different compared with the other studies conducted in Southeast Asia. In this study, the density of An. maculatus was found to be lower than that of the other four species; meanwhile, it was found to be predominant in several countries of Indochina peninsula [4, 10-12]. Furthermore, An. farauti and An. punctulatus are predominant in Papua New Guinea and An. sondaicus is commonly found in Sunda Island, Indonesia $[13,25,26]$. It seems there is great diversity 
in species that contributes to malaria transmission between different areas in Southeast Asia. However, all studies stated that Anopheles mosquito tends to be more active during the first hour of the evening, which is in accordance with the findings of this study. Nevertheless, this study provided additional data about Anopheles species in Indonesia which still has high prevalence of malaria.

\section{Conclusion}

Based on the results of this study, we found that An. kochi and An. barbirostris were the main vectors of malaria in Southern Minahasa district, with An. barbirostris feeding specifically on humans and An. kochi feeding on both humans and animals. It also appears that they tend to be more active during the first hour of the evening whereas their activity drops significantly later on. In regard to An. kochi's feeding behavior, it can be concluded that having a domestic animal around the settlement could attract this species and, hence, increase the risk of malaria infection. However, further research is needed to investigate the Plasmodium infestation rate among these Anopheles species in order to complete the map of species distribution and susceptibility areas in Minahasa Region and Indonesia.

\section{Conflicts of Interest}

The authors certify that they have no affiliation with or involvement in any organization or entity with any financial interest (such as honoraria; educational grants; participation in speakers' bureaus; membership, employment, consultancies, stock ownership, or other equity interests; and expert testimony or patent-licensing arrangements) or nonfinancial interest (such as personal or professional relationships, affiliations, knowledge, or beliefs) in the subject matter or materials discussed in this manuscript.

\section{Authors' Contributions}

All authors contributed equally in the processing and writing of this research.

\section{References}

[1] I. M. Sudarmaja and I. K. Swastika, "Effectiveness of different detergent solutions as larviside for Aedes aegypti larvae," Bali Medical Journal, vol. 4, no. 1, pp. 41-43, 2015.

[2] World Health Organization, Fact Sheet: World Malaria Report 2015, 2015.

[3] Indonesia Health Ministry, Health Database per District, 2016.

[4] H. D. Trung, W. Van Bortel, T. Sochantha, K. Keokenchanh, O. J. T. Briët, and M. Coosemans, "Behavioural heterogeneity of anopheles species in ecologically different localities in Southeast Asia: a challenge for vector control," Tropical Medicine and International Health, vol. 10, no. 3, pp. 251-262, 2005.

[5] K. Bashar, N. Tuno, T. U. Ahmed, and A. J. Howlader, "Bloodfeeding patterns of Anopheles mosquitoes in a malaria-endemic area of Bangladesh," Parasites \& Vectors, vol. 5, p. 39, 2012.
[6] A. I. Jiram, I. Vythilingam, Y. M. Noorazian, Y. M. Yusof, A. H. Azahari, and M.-Y. Fong, "Entomologic investigation of Plasmodium knowlesi vectors in Kuala Lipis, Pahang, Malaysia," Malaria Journal, vol. 11, article no. 213, 2012.

[7] C. T. O'Connor and A. Soepanto, Kunci Bergambar Nyamuk Anopheles Dewasa di Indonesia, Dit.Jen. PPM \& PLP, Jakarta, Indonesia, 1999.

[8] F. S. Barros and N. A. Honório, "Man biting rate seasonal variation of malaria vectors in Roraima, Brazil," Memórias do Instituto Oswaldo Cruz, vol. 102, no. 3, pp. 299-302, 2007.

[9] H. M., B. K., R. K.M.Z., R. M.A., and H. A.J., "Biting rhythms of selected mosquito species (Diptera: Culicidae) in Jahangirnagar University, Bangladesh," Journal of Mosquito Research, vol. 5, no. 8, pp. 1-5, 2016.

[10] P. Sriwichai, Y. Samung, S. Sumruayphol et al., "Natural human Plasmodium infections in major Anopheles mosquitoes in western Thailand," Parasites and Vectors, vol. 9, no. 1, article 17, 2016.

[11] C. D. Manh, N. W. Beebe, V. N. T. Van et al., "Vectors and malaria transmission in deforested, rural communities in north-central Vietnam," Malaria Journal, vol. 9, p. 259, 2010.

[12] I. Vythilingam, R. Phetsouvanh, K. Keokenchanh et al., "The prevalence of Anopheles (Diptera: Culicidae) mosquitoes in Sekong Province, Lao PDR in relation to malaria transmission," Tropical Medicine and International Health, vol. 8, no. 6, pp. 525-535, 2003.

[13] K. A. Barbara, S. Sukowati, S. Rusmiarto, D. Susapto, M. J. Bangs, and M. H. Kinzer, "Survey of anopheles mosquitoes (Diptera: Culicidae) in West Sumba District, Indonesia," Southeast Asian Journal of Tropical Medicine and Public Health, vol. 42, no. 1, pp. 71-82, 2011.

[14] E. Ndoen, C. Wild, P. Dale, N. Sipe, and M. Dale, "Relationships between anopheline mosquitoes and topography in West Timor and Java, Indonesia," Malaria Journal, vol. 9, no. 1, article 242, 2010.

[15] O. R. Pinontoan, The Temperature Relationship, Relative Humidity, and The Height of The Place with The Presentation of Mosquitoes Anopheles Invested with Plasmodium falciparum in Minahasa District South of North Sulawesi Province [Dissertation, thesis], 2008.

[16] N. S. Idris-Idram, M. Sudomo, S. Soejitno, and S. Saptoro, "Anopheles SundaicusVektor Malaria Di Daerah Pantai BekasHutan Mangrove Di Kecamatan Padang Cermin, Kabupaten Lampung Selatan," Indonesia Buletin Penelitian Kesehatann, vol. 28, no. 3, pp. 1-10, 2000.

[17] S. K. Parida, R. K. Hazra, N. Marai, H. K. Tripathy, and N. Mahapatra, "Host feeding patterns of malaria vectors of Orissa, India," Journal of the American Mosquito Control Association, vol. 22, no. 4, pp. 629-634, 2006.

[18] M. E. Sinka, M. J. Bangs, S. Manguin et al., "The dominant Anopheles vectors of human malaria in the Asia-Pacific region: occurrence data, distribution maps and bionomic précis," Parasites \& Vectors, vol. 4, no. 1, article 89, 2011.

[19] M. S. Alam, M. G. M. Khan, N. Chaudhury et al., "Prevalence of anopheline species and their Plasmodium infection status in epidemic-prone border areas of Bangladesh," Malaria Journal, vol. 9, no. 1, article 15, 2010.

[20] J. C. Lien, B. A. Kawengian, F. Partono, B. Lami, and J. H. Cross, "A brief survey of the mosquitoes of South Sulawesi, Indonesia, with special reference to the identity of Anopheles barbirostris (Diptera: Culicidae) from the Margolembo area.," Journal of Medical Entomology, vol. 13, no. 6, pp. 719-727, 1977. 
[21] R. D. Cooper, M. D. Edstein, S. P. Frances, and N. W. Beebe, "Malaria vectors of timor-leste," Malaria Journal, vol. 9, no. 1, article 40, 2010.

[22] P. H. Amerasinghe, F. P. Amerasinghe, F. Konradsen, K. T. Fonseka, and R. A. Wirtz, "Malaria vectors in a traditional dry zone village in Sri Lanka," The American Journal of Tropical Medicine and Hygiene, vol. 60, no. 3, pp. 421-429, 1999.

[23] J. A. Reid, B. A. Harrison, and S. Atmosoedjono, "Variation and vector status in barbirostris," MosqSyst, vol. 11, pp. 235-251, 1979.

[24] M. Soekirno, K. Santijo, A. A. Nadjib et al., "Fauna Anopheles dan Status, Pola Penularanserta Endmisitas Malaria di Halmahera, Maluku Utara," Cermin DuniaKedokteran, vol. 118, pp. 1519, 1997.

[25] B. St. Laurent, S. Supratman, P. B. S. Asih et al., "Behaviour and molecular identification of Anopheles malaria vectors in Jayapura district, Papua province, Indonesia," Malaria Journal, vol. 15, no. 1, article 1234, 2016.

[26] R. D. Cooper, D. G. E. Waterson, S. P. Frances, N. W. Beebe, B. Pluess, and A. W. Sweeney, "Malaria vectors of Papua New Guinea," International Journal for Parasitology, vol. 39, no. 13, pp. 1495-1501, 2009. 


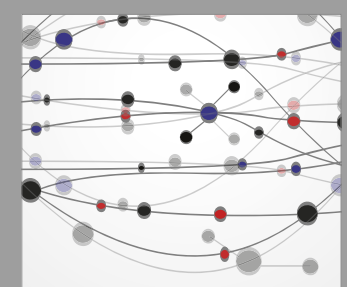

The Scientific World Journal
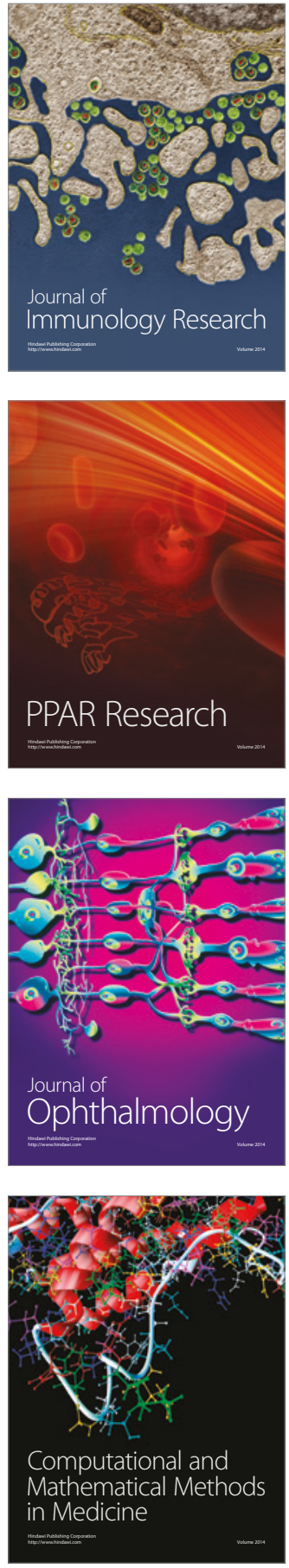

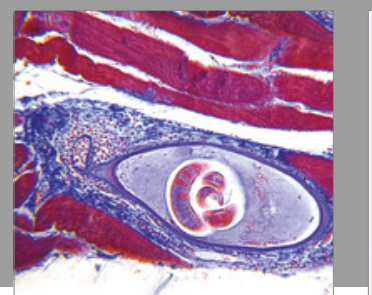

Gastroenterology Research and Practice
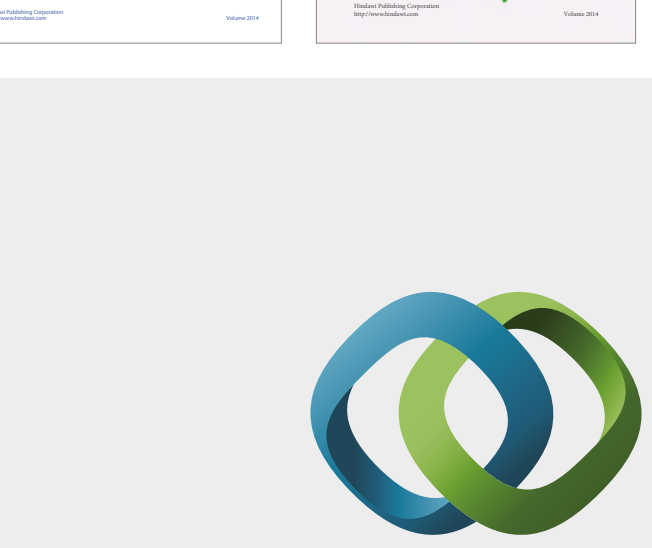

\section{Hindawi}

Submit your manuscripts at

https://www.hindawi.com
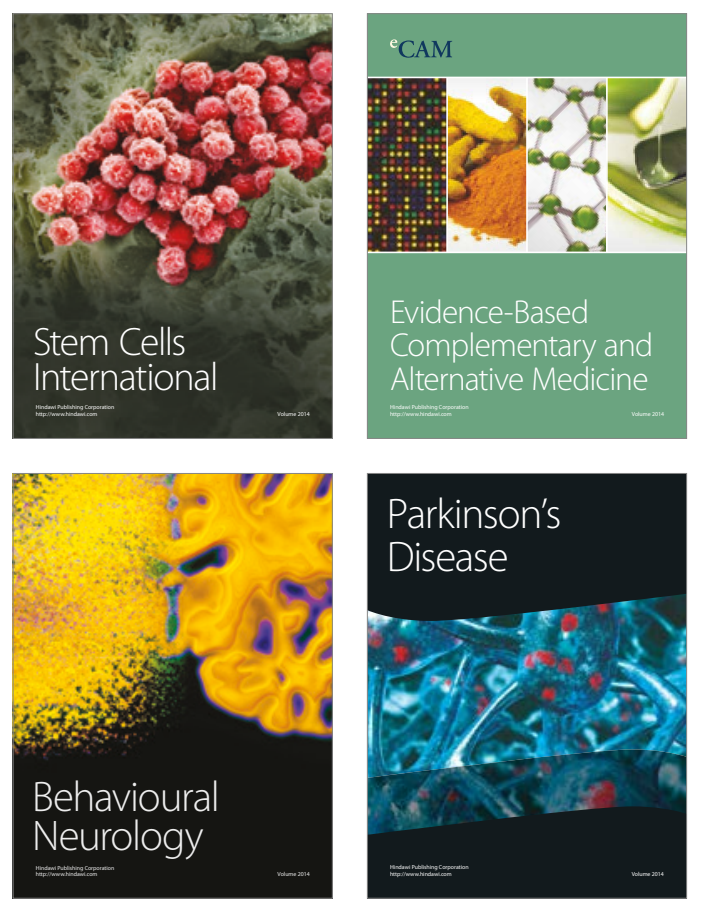
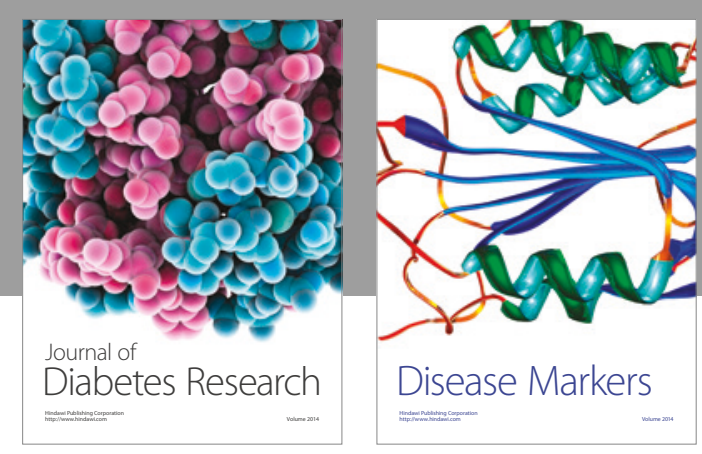

Disease Markers
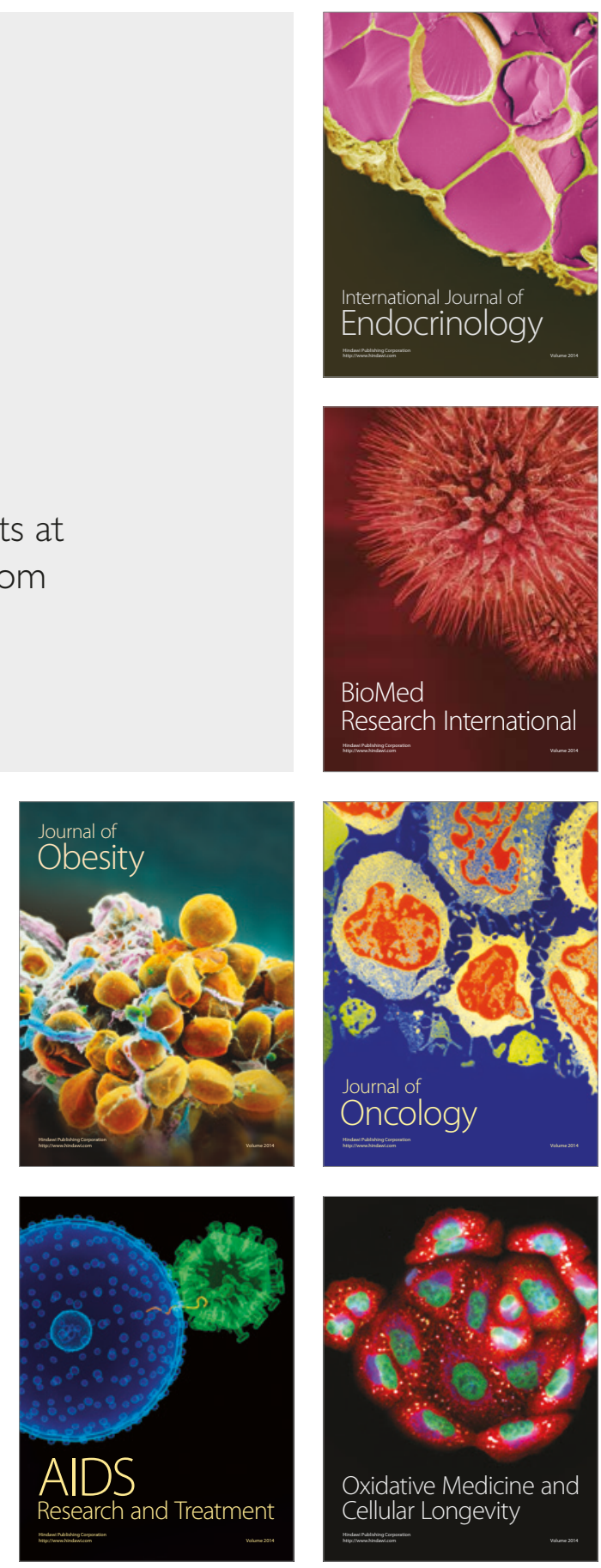